\title{
Development of Grogged Clay Used Water-purified-sludge
}

\author{
Jae-Jin Jeong, Yong-Seok Lee, and Byung-Ha Lee ${ }^{\dagger}$ \\ Department of Materials Science \& Engineering, Myongji University, Yongin 449-728, Korea \\ (Received April 22, 2014; Revised June 19, 2014; Accepted July 1, 2014)
}

\author{
정수슬러지를 사용한 조합토의 개발 \\ 정재진 · 이용석 · 이병하 ${ }^{\dagger}$ \\ 명지대학교 신소재공학과 \\ (2014년 4월 22일 접수 ; 2014년 6월 19일 수정 ; 2014년 7월 1일 채택)
}

\begin{abstract}
People could not imagine living without tab water. However, the water filtering process at a purification plant used to produce tab water creates tons of sludge, which is generally wasted. This sludge waste consists of (1) mineral elements, such as sand, (2) organic materials, and (3) a coagulant, which agglomerates the two. As an enormous amount of sludge waste is generated every year, numerous studies have been carried out to identify how to deal with this problem. Currently, however, most of the sludge waste is directly discarded in landfills. In the present study, water-purified sludge waste received a heat treatment at $1300^{\circ} \mathrm{C}$ and was then ground into particles to be used as a ceramic material. Next, the resultant particles were compounded with chamotte substitutes to produce grogged clay that is suitable for wheel-throwing ceramics. Consequently, the plasticity of the sludge waste decreased as the content of calcination increased. Thus, it is considered that wheel throwing is available only up to PBF-3. Thus, it is available for wheel throwing and has a high strength of $864 \mathrm{kgf} / \mathrm{cm}^{2}$ with less than 0.2 percent of porosity and absorption ratio were displayed in PBF-2 at $1280^{\circ} \mathrm{C}$ with 20 percent of calcination from the purified sludge. Therefore, the PBF-2 body produced in this study was considered to be capable of replacing grogged clay in the market.
\end{abstract}

Key words : Recycling, Water-purified-sludge, Mullite, Grogged clay, Ceramic body

\section{1. 서 론}

물(Water)은 인류 생활에 있어 중요한 자원이다. 자연에 있어서 물의 중요성은 언급할 나위 없이 인체에 있어서 도 $70 \%$ 정도가 수분으로 구성되어 있는 만큼 물 없이는 우리의 생활을 영위할 수 없다. 이러한 중요성 때문에 세 계적으로도 물을 확보하고 관리하는데 큰 노력을 기울이 고 있다.

현재 우리가 마시는 물은 강이나 지하수에서 채취하는 담수가 대부분으로서 상수지역의 보호 등에 의해 깨끗이 보존되고 있으나, 상수원에서의 미생물, 세균, 잔여이물질 등의 포함에 의해 직접 음용하는 것이 어렵기 때문에 정 수설비를 통해 정화된 물을 마시거나 또한 사용하고 있 다. 이러한 물의 정화에는 고도정수처리 기술이 사용되고 있으며, 더욱 깨끗한 물을 제공하기 위한 많은 연구와 노 력이 행해지고 있다.

\footnotetext{
${ }^{\dagger}$ Corresponding author : Byung-Ha Lee

E-mail : lbh@mju.ac.kr

Tel : +82-31-330-6461 Fax : +82-31-330-6469
}

우리나라의 정수장에서는 일반적으로 취수 후 침전-여 과-약품처리 등의 공정을 반복하고, 수질검사를 거친 다 음에야 양수장, 배수지를 통해 정수를 사용할 수 있게 된 다. 이 때 문제가 되고 있는 것이 원수의 불순물을 제거 하는 침전과 여과공정에서 발생되는 정수슬러지이다. 이 정수슬러지는 상수원의 환경변화에 따라 유기물질의 함 량은 조금 차이가 발생하지만, 대부분 모래 등의 무기성 분과 이를 응집하기 위해 사용된 응집제로 구성되어 있 고, 그 양 또한 2008년 통계를 보면 연간 약 26만톤의 막 대한 양이 발생되고 있고 생활이 윤택해짐에 따라 그 양 은 지속적으로 늘어나고 있는 추세이다.

이 정수슬러지는 대부분 실리카 $\left(\mathrm{SiO}_{2}\right)$ 와 알루미나 $\left(\mathrm{Al}_{2} \mathrm{O}_{3}\right)$ 로 구성되어 있어 무기계 원료로서의 재활용이 기대되어 지나 현재까지 직매립이나 소각에 의존하고 있는 실정으 로 2차적인 환경문제를 일으킬 가능성이 높아 이를 재활 용하기 위한 다양한 방법의 고안이 필요하다. 재활용을 위한 많은 선행연구 ${ }^{1-14)}$ 들이 행해지고 있으며, 그 중 정수 슬러지를 사용한 고형화 공정의 개발이나 점토벽돌, 제올라 이트 및 다공성물질의 합성에 관한 연구가 대표적으로 진행 
되고 있지만 산업적으로 적용되는 양은 그다지 많지 않다.

본 연구에서는 현재 정수처리에 사용된 후 대부분 직 매립에 의해 폐기되어지고 있는 정수슬러지를 기능성 도 자기소지 중 조합토의 원료로서 재활용하고자 한다. 조합 토는 점토소지에 조립의 샤모트(chamotte)를 20 30\% 혼 합한 소지로서 수축율을 적게하여 건조수축 및 소성수축 시 발생하는 균열이 적도록 조절 가능하며, 열간 하중연 화값이 적어 큰 규모의 조형물이나 테라코타 등에 사용 해도 파손이 적은 작품을 제작할 수 있어 많은 도예가들 이 작품 제작에 널리 사용하고 있다. 하지만, 알루미나 함 량이 많아 중량이 무겁고, 높은 소성온도, 낮은 소성강도 및 비교적 조립이기 때문에 도예의 섬세한 작업이 어렵 다는 점, 초벌구이 후의 시유시나 재벌구이 후의 제품에 있어 높은 투수성과 이로 인한 동파 등의 문제는 해결해 야 할 과제로 남아있다.

따라서 이러한 조합토의 문제에 대해 정수슬러지를 샤 모트의 대체 원료로 사용할 수 있도록 열처리, 분쇄 등의 공정을 확립하고, 이를 도자기 소지에 혼합시킴에 의해 물레성형 및 섬세한 작업까지 가능한 새로운 조합토로의 개발을 진행하고자 한다.

이에 본 새로운 도예용 소지의 개발 연구는 정수슬러 지의 무분별한 폐기 상황 하에서 발생되어지고 있는 폐 기물의 대량 발생, 폐기절차에 의한 경제적 부담, 환경오 염의 문제를 해결하는데 조금이나마 도움이 될 수 있을 것이다.

\section{2. 실험 방법}

\section{1. 출발원료 준비}

정수슬러지는 침전 및 여과의 정수과정에서 발생하는 유기물질, 부유물질 및 이를 응집하는 응집제를 탈수, 건 조한 물질이다. 성분분석을 위해 행한 $\mathrm{XRF}(\mathrm{XRF} 1800$, Shimadzu, Japan) 분석 결과로 Table 1에 보인 바와 같이 모래 등의 부유물질에서 관찰되는 약 $33 \mathrm{wt} \%$ 의 실리카와 정수 시 응집제로 주로 사용되고 있는 폴리알루미늄클로 라이드(Poly aluminium chloride)에서 관찰되는 알루미나 가 약 $53 \mathrm{wt} \%$ 로 주성분을 이루고 있으며, 하소시 30 $50 \mathrm{wt} \%$ 정도 수분 증발, 유기물질의 분해로 인해 강열감 량이 나타났다.

이 정수슬러지를 도예용 소지의 하나인 조합토의 원료 로서 사용하기 위해서는 열처리에 의한 하소분을 제조하 는 공정이 필요하다. 이에 열간 변화가 일어나지 않는 적 정한 열처리 온도를 확인하기 위하여 $1150 \sim 1350^{\circ} \mathrm{C}$ 온도
구간에서 $50^{\circ} \mathrm{C}$ 간격으로 열처리를 행하고 $\mathrm{X}$ 선회절분석 (XRD7000, Shimadzu, Japan)에 의해 분석을 행하고 그 결 과를 Fig. 1에 나타내었다. 정수슬러지에서는 quartz가 확 인되었으며, 열처리 온도의 상승에 따라 $1000^{\circ} \mathrm{C}$ 부근에서 부터 mullite상이 조금씩 생성되기 시작하였다. 이후 $1150^{\circ} \mathrm{C}$ 열처리 영역에서부터는 quartz상은 거의 확인되지 않고 mullite상만이 확인되었으며, 열처리 온도 상승에도 불구 하고 결정상에 큰 변화는 확인되지 않았다. 이에 샤모트 를 대체하는데 필요한 정수슬러지 하소분의 열처리온도 는 일반적인 도자기소성온도인 $1250^{\circ} \mathrm{C}$ 보다 높은 $1300^{\circ} \mathrm{C}$ 로 정하고, 물레성형용으로의 조합토 적용을 위해 열처리 후의 정수슬러지 하소분은 분쇄공정에 의해 $200 \mathrm{mesh}$ 전 통시킨 분말을 준비하였다.

여기에 가소성 부여를 위해 현재 시판되어지고 있는 도 자기 제조용 백자소지의 조성으로 Table 2에 보인 와목점 토, 하동고령토, 태백도석, 부여규석으로 조합을 행하였다. 재활용을 위한 조합토 조합으로서 $1300^{\circ} \mathrm{C}$ 로 열처리한 정 수슬러지 하소분과 백자소지를 $0 \sim 50 \%$ 의 범위에서 조정 하여 각각 조합을 하였다. 여기에서 출발원료로 백자소지 를 기준 조성으로 한 것은 세라믹소지로의 적용을 검증 을 위한 것으로, 가소성 부여 뿐 아니라 검증 후 색소지 로의 활용을 검증하기 위한 것이다. Table 3에 본 실험의 조합비를 나타내었다.

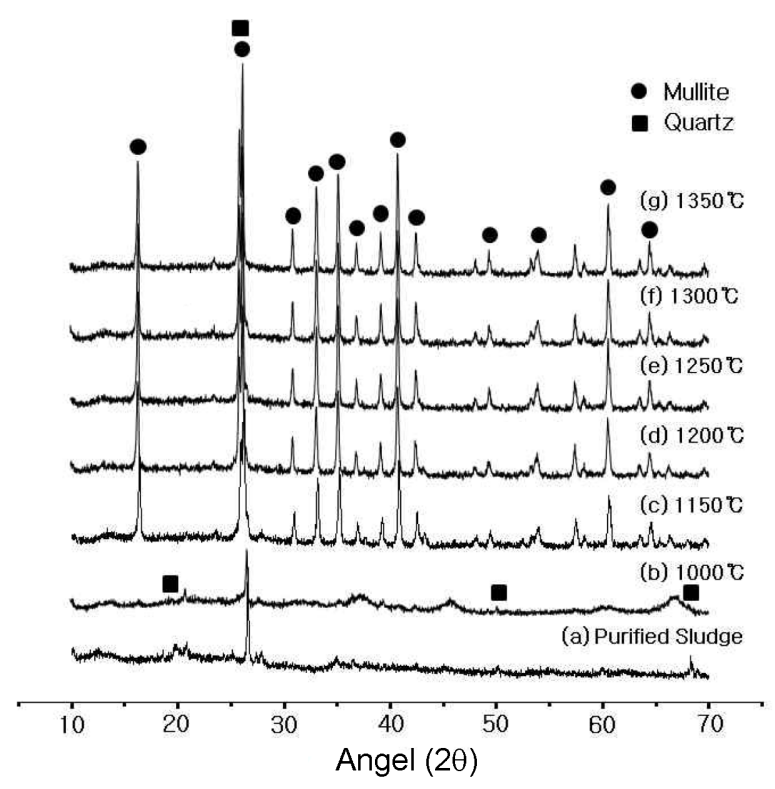

Fig. 1. X-ray diffraction patterns of water-purified-sludge with the different calcined temperatures.

Table 1. Chemical Composition of a Water-purified-sludge (wt \%)

\begin{tabular}{cccccccccc}
\hline Materials & $\mathrm{K}_{2} \mathrm{O}$ & $\mathrm{Na}_{2} \mathrm{O}$ & $\mathrm{CaO}$ & $\mathrm{MgO}$ & $\mathrm{TiO}_{2}$ & $\mathrm{Fe}_{2} \mathrm{O}_{3}$ & $\mathrm{Al}_{2} \mathrm{O}_{3}$ & $\mathrm{SiO}_{2}$ & Ig.loss \\
\hline Purified sludge & 1.2620 & 0.1960 & 1.0730 & 0.8990 & 0.8320 & 4.9010 & 53.5680 & 33.1520 & 12.5700 \\
\hline
\end{tabular}


Table 2. Composition \& Chemical Composition of a Pottery Body (wt\%)

\begin{tabular}{|c|c|c|c|c|c|c|c|c|c|}
\hline \multirow{2}{*}{$\begin{array}{c}\text { Standard body composition } \\
\text { PB }\end{array}$} & \multicolumn{3}{|c|}{ Kairome Clay } & \multicolumn{2}{|c|}{ Hadong Kaolin } & \multicolumn{2}{|c|}{ Teabeck Potterystone } & \multicolumn{2}{|c|}{ Buyeo Quartz } \\
\hline & & 45 & & 15 & & 20 & & 20 & \\
\hline Materials & $\mathrm{K}_{2} \mathrm{O}$ & $\mathrm{Na}_{2} \mathrm{O}$ & $\mathrm{CaO}$ & $\mathrm{MgO}$ & $\mathrm{TiO}_{2}$ & $\mathrm{Fe}_{2} \mathrm{O}_{3}$ & $\mathrm{Al}_{2} \mathrm{O}_{3}$ & $\mathrm{SiO}_{2}$ & Ig.loss \\
\hline Kairome Clay & 0.4600 & 0.0700 & 0.1700 & 0.3100 & 0.4000 & 1.4200 & 32.6500 & 51.2400 & 12.5700 \\
\hline Hadong Kaolin & 2.5600 & 1.1500 & 0.8700 & 0.4000 & 0.1500 & 0.6700 & 34.4000 & 47.2000 & 11.6000 \\
\hline Teabeck Potterystone & 1.8617 & 0.1876 & 0.5947 & 0.2515 & 0.0502 & 0.4445 & 14.8607 & 82.9493 & - \\
\hline Buyeo Quartz & 0.0100 & 0.0300 & 0.0200 & 0.0100 & - & 0.0330 & 0.0600 & 99.3600 & - \\
\hline
\end{tabular}

Table 3. Mixture Content of a Pottery Body and Water-purifiedsludge

\begin{tabular}{ccc}
\hline & Standard body & $\begin{array}{c}\text { Purified Sludge } \\
\left(1300^{\circ} \mathrm{C},<75 \mu \mathrm{m}\right)\end{array}$ \\
\hline PBF-0 & 100 & 0 \\
PBF-1 & 90 & 10 \\
PBF-2 & 80 & 20 \\
PBF-3 & 70 & 30 \\
PBF-4 & 60 & 40 \\
PBF-5 & 50 & 50 \\
PBF-C & grogged clay (D 사 , KOREA) \\
\hline
\end{tabular}

\section{2. 실험 방법}

\subsection{1. 소지조합 및 성형}

정수슬러지의 재활용에 의한 새로운 도자기 소지로의 활용을 목적으로 Table 3 의 조성에 따라 각각 칭량한 후 볼밀에 의해 24시간 혼합하고 건조한 후, 다시 가소수를 첨가하여 가소성을 부여한 후 각 시험편을 제작하였다.

각 조성에 따른 소지에 대한 물리·화학적 특성을 측정 하기 위하여 강도 측정용으로 $6 \times 8 \times 45 \mathrm{~mm}$ 의 막대(bar) 형 및 휨 측정용으로 $30 \times 8 \times 130 \mathrm{~mm}$ 의 막대(bar)형, 겉 보기밀도 및 흡수율 측정용으로 $\phi 25 \times 4 \mathrm{~mm}^{2}$ 의 원주(disc) 형 시험편을 석고몰드를 사용한 가압성형법을 이용하여 제작하였다.

\subsection{2. 건조 및 소성}

성형한 시험편이 휨이나 갈라짐, 부분건조가 되는 것을 방지하기 위하여 $4 \mathrm{~h}$ 간격으로 위치를 조절하며, 4 일 동 안 자연 건조시킨 후 건조기로서 완전 건조를 행하였다. 소성은 실리코니트 머플로(siliconite muffle furnace)를 사 용하여, 상온 $\sim 900^{\circ} \mathrm{C}$ 까지는 $5{ }^{\circ} \mathrm{C} / \mathrm{min}, 900^{\circ} \mathrm{C}$ 에서 소성온 도인 $1260 \sim 1300^{\circ} \mathrm{C}$ 까지는 $3{ }^{\circ} \mathrm{C} / \mathrm{min}$ 로 승온하여 1 시간 유 지한 후 자연 냉각하는 소성스케쥴로 소성하였다.

\section{3. 특성분석}

\subsection{1. 가소성 측정}

가소성은 제품의 성형성과 밀접한 관계가 있는 특성이 나, 이에 따른 가소성 측정방법은 현재까지 규격화된 측 정 방법이 확립되어 있지 않다. 따라서 도자기 제조업체 에서 시행하고 있는 소지를 일정한 굵기의 긴 bar형으로 만든 후 이를 손가락에 감았을 때 균열이 생기는 정도를 보고 가소성을 판단하는 방법인 coiling법에 의해 가소성 을 평가하였다. 이는 와목점토의 가소성치를 10 으로 하였 을 때의 각 조성의 소지의 가소성치를 평가하는 방법이다.

\subsection{2. 물성 측정}

조합토로 사용되기 위해서는 성형성 뿐만 아니라 물리 적 특성인 수축율, 흡수율, 기공율의 평가가 필요하다. 또 한 기계적 물성도 충족되어야 한다. 이에 KS L 3114에 의해 소성된 시험편의 수축율, 흡수율, 기공율 측정을, $\mathrm{KS}$ L1591에 의한 3점 굽힘강도 시험법으로 UTM (MKS Type-PP-650-D, Scientific Instrument, Japan)을 사용하여 강도를 측정하였다.

\subsection{3. 미세구조 및 결정변화 분석}

각 조성에 따른 시험편의 미세구조는 SEM (SS-550, Shimadzu, Japan)을 사용하여 관찰하였다. 또한 재소성에 의한 결정성 변화는 X선회절분석기 (XRD7000, Shimadzu, Japan)를 이용하여 관찰하였다.

\section{3. 결과 및 고찰}

\section{1. 가소성 분석}

도자기 제조에 있어 가소성은 의도하는 제품을 완벽히 재현할 수 있는지 결정하는 매우 중요한 특성이다. 일반 적으로 샤모트는 비가소성원료로 기본소지로의 첨가에 의 해 상당히 가소성을 떨어질 것으로 예측되었다. 본 실험 에서의 각 조합들도 $1300^{\circ} \mathrm{C}$ 로 열처리한 정수슬러지 하소 분의 혼합에 의해 가소성이 떨어질 것으로 예상되어지나, 
Table 4. Result of Plasticity of Each Composition

\begin{tabular}{ccccccccc}
\hline Composition & Kairome Clay & PBF-0 & PBF-1 & PBF-2 & PBF-3 & PBF-4 & PBF-5 & PBF-C \\
\hline Value & 10 & 9 & 8.5 & 8.0 & 7 & 6 & 5 & 7 \\
\hline
\end{tabular}

성형이 가능한 가소성의 한계를 확인해 보고자 coiling법 으로 평가를 행하고 그 결과를 Table 4에 나타내었다. 결 과에서 보이는 바와 같이 와목점토를 기준으로, 정수슬러 지 하소분이 들어가지 않은 조성인 $\mathrm{PBF}-0$ 는 9의 값을 나 타내었으며, 이 후 정수슬러지 샤모트의 첨가에 의해 가 소성값은 점점 낮아졌으며, $40 \%$ 들어간 PBF-4 조성에서 는 6 이하의 값을 나타내어 물레성형이 어려울 것으로 판 단되었다. 이에 비해 비교치로서 현재 시판되어지고 있는 조합토인 $\mathrm{PBF}-\mathrm{C}$ 에서는 굵은 샤모트 입자를 포함하고 있 음에도 불구하고 오히려 7 정도의 가소성을 나타내고 있 는데, 이는 소지 조합에 있어 비가소성을 보완하기 위하 여 가소성 점토를 좀 더 첨가한 결과로 판단된다.

\section{2. 물성분석}

Table 3의 각 조성을 시험편으로서 제작하고 1260 $1300^{\circ} \mathrm{C}$ 에서 각각 1 시간 소성한 후, 각각의 물성을 측정하 였다. 소성된 시험편의 외관은 전반적으로 정수슬러지 하 소분 함량의 증가에 따라 충분히 소결이 이루어지지 않 는 것으로 관찰되었다. 이는 $1300^{\circ} \mathrm{C}$ 로 열처리된 정수슬러 지가 기본소지와의 반응이 이루어지는 충분한 함량 이상 으로 혼합되었기 때문으로 생각되어졌으며, 이는 기본 물 성에 영향을 미칠 것으로 보여졌다.

다음으로 $1260 \sim 1300^{\circ} \mathrm{C}$ 로 소성된 각 조성의 시험편에 대해 기본 물성을 평가하였다. 먼저 Fig. 2에 $1280^{\circ} \mathrm{C}$ 로 소 성한 각 조성의 시험편에 대한 수축률 변화를 확인하였 다. 정수슬러지 하소분의 혼합량 증가에 따라 건조수축율 은 기본소지만으로 된 $\mathrm{PBF}-0$ 의 $3.9 \%$ 에서 점점 감소하여

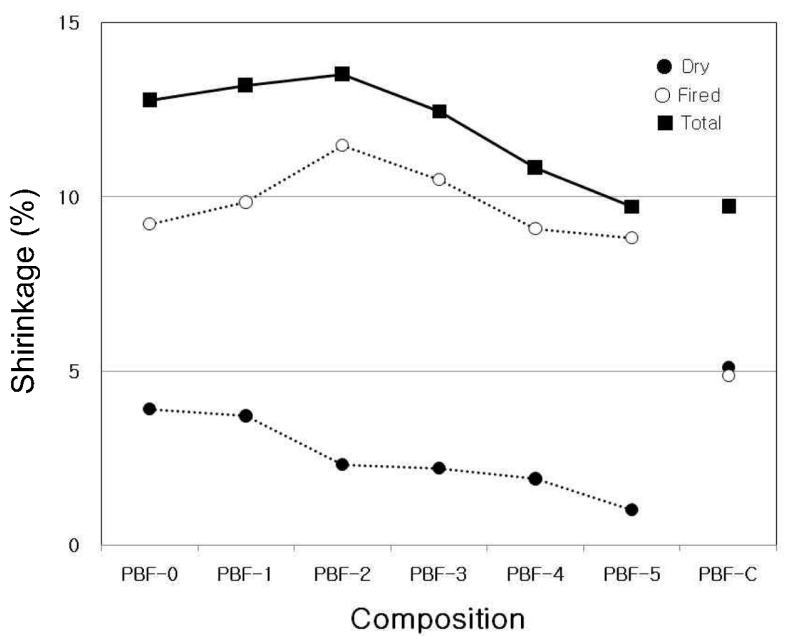

Fig. 2. Shrinkage of the specimens sintered at $1280^{\circ} \mathrm{C}$.
$50 \%$ 인 PBF-5에서 $1.0 \%$ 까지 낮아졌으며, 기존 조합토인 $\mathrm{PBF}-\mathrm{C}$ 의 $5.1 \%$ 보다 매우 낮은 값을 나타내었다. 이는 정 수슬러지 하소분을 미분으로 사용함으로서 입자와 입자 사이가 충분히 충진되어져 공극이 많은 기존의 조합토보 다 낮은 건조수축율을 나타내었다고 볼 수 있다. 반면에 소성수축율에서는 기존 조합토인 $\mathrm{PBF}-\mathrm{C}$ 가 $4.8 \%$ 로 낮은 값을 나타내는데 반해, 정수슬러지 하소분 혼합량 증가에 따라 $20 \%$ 혼합한 $\mathrm{PBF}-2$ 조성에서 $11.4 \%$ 까지 증가하다가 이후 감소하여 $50 \%$ 첨가된 $\mathrm{PBF}-5$ 에서는 $8.8 \%$ 까지 낮아 졌다. 이는 완전한 샤모트화 되지 못한 정수슬러지 하소 분이 기본소지와의 일부 반응 등에 의해 수축이 증가하 다가, 다시 하소분 함량 증가에 따라 미반응 하소분의 증 가 및 기공의 발달 등에 의해 수축율이 낮아진 것으로 판 단된다.

또한, 각 조성에서의 기공율 및 흡수율의 변화를 관찰 하고, 그 중 $1280^{\circ} \mathrm{C}$ 와 $1300^{\circ} \mathrm{C}$ 소성 시험편에 대한 결과 를 Fig. 3에 나타내었다. 기공율과 흡수율의 경우, 정수슬 러지 하소분이 함유되지 않은 PBF-0 조성에서부터 $30 \%$ 혼합된 PBF-3 조성까지는 모든 온도에서 기공율은 $0.2 \sim 1.3 \%$, 흡수율은 $0.2 \sim 0.6 \%$ 정도의 값을 나타내어 충 분히 소결이 이루어진 것으로 보여졌으나, 정수슬러지 하 소분이 $40 \%$ 이상 포함된 PBF-4 이상의 조성에서는 기공 율 $2.8 \sim 8.0 \%$, 흡수율은 $6.3 \sim 17.0 \%$ 까지 급격히 증가하였 다. 정수슬러지의 함량 증가에 의해 소결 및 유리상 생성 에 영향을 미치는 기본 소지의 양이 적어 공극을 충분히 메우지 못해 미세기공이 많이 존재하기 때문이라 판단된다.

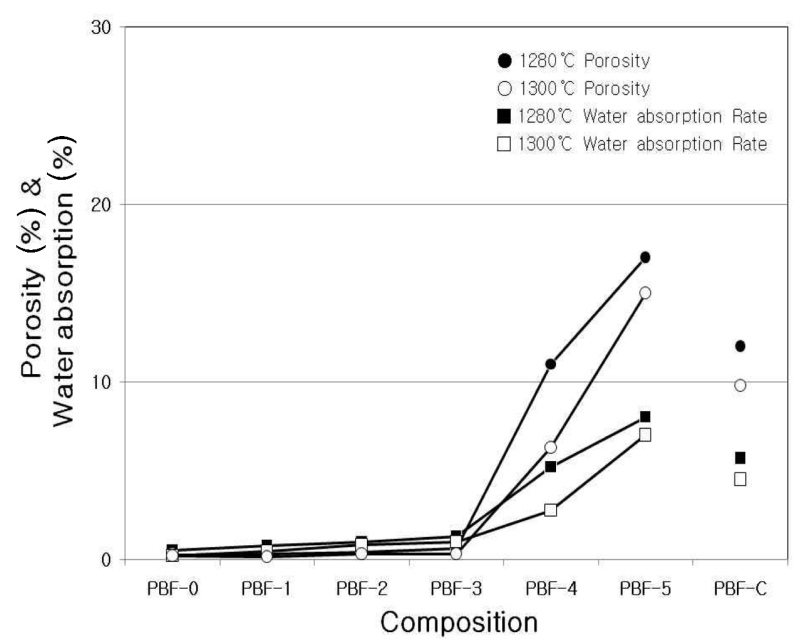

Fig. 3. Porosity and water absorption of the specimens sintered at $1280^{\circ} \mathrm{C}$ and $1300^{\circ} \mathrm{C}$. 
다음으로 열간 하중연화 분석을 행하였다. 일반적인 조 합토의 경우 대형기물이나 조형에 가까운 작품에 적용이 많은 소지로서 적은 열간 하중연화 특성이 또한 중요하 다. 이에 본 실험의 조성에서도 각 소성온도에 따른 열간 하중연화 특성을 측정하고 그 결과를 Fig. 4에 나타내었 다. 결과에서와 같이 모든 소성온도에서 정수슬러지 하소 분의 양이 증가함에 따라 하중연화값은 낮아지는 경향을 보이고 있으며, 정수슬러지 하소분이 $40 \%$ 들어간 PBF-4 이상의 조성에서는 충분한 소결이 진행되지 않아 거의 변

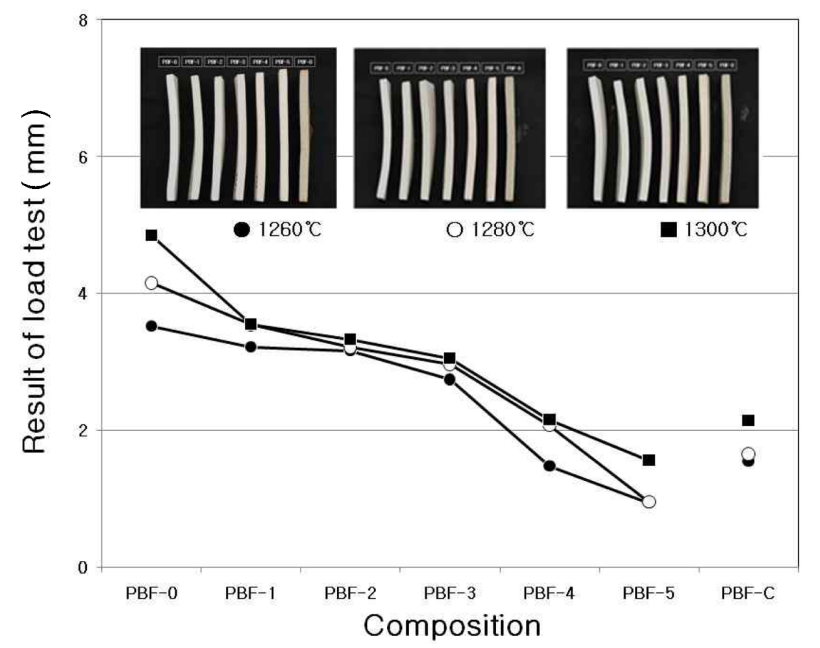

Fig. 4. Results of load testing of the specimens inset is the photos of samples.
형이 일어나지 않은 것으로 확인되었다. 그 외의 조성에 서는 미립의 정수슬러지 하소분의 양이 부족하여 소성 시 일부 반응이 일어나 지지대 역할을 해 주지 못해 일부 변 형이 온 것으로 보여지나, 기본 소지인 PBF-0 보다는 모 든 조성에서 낮은 값을 보였다.

이러한 물성의 변화는 소성에 의한 미세구조에 기인한 다고 보여진다. 이에 각 소성온도에 따른 굽힘강도를 측 정하고 그 결과를 Fig. 5에, 이 때의 SEM에 의한 미세구 조 분석 결과를 Fig. 6에 각각 나타내었다.

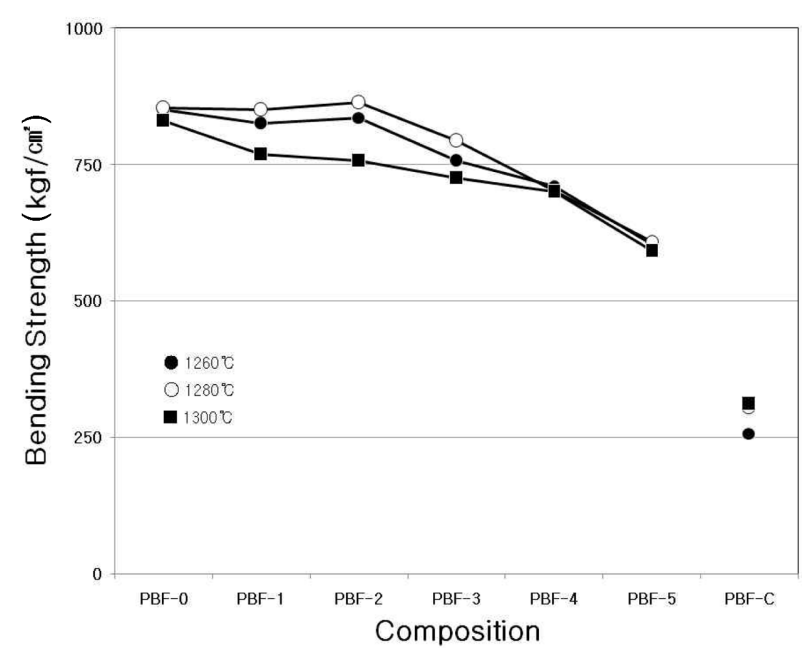

Fig. 5. Bending strength of the specimens sintered at different temperatures.

\begin{tabular}{|c|c|c|c|c|}
\hline Composition & PBF-0 & PBF-1 & PBF-2 & PBF-3 \\
\hline \multicolumn{5}{|l|}{$1280^{\circ} \mathrm{C}$} \\
\hline Composition & PBF-4 & PBF-5 & & PBF-C \\
\hline \multicolumn{5}{|l|}{$1280^{\circ} \mathrm{C}$} \\
\hline Temperature & $1260^{\circ} \mathrm{C}$ & $1280^{\circ} \mathrm{C}$ & $1300^{\circ} \mathrm{C}$ & \\
\hline PBF-3 & & & & \\
\hline
\end{tabular}

Fig. 6. SEM fracture surface images of specimens sintered at $1280^{\circ} \mathrm{C}$ and PBF-3 sintered at each temperature $(\times 1000)$. 
굽힘강도 측정 결과인 Fig. 5 에서 보면, $1280^{\circ} \mathrm{C}$ 에서 소 성한 시험편의 경우, 정수슬러지 하소분이 $20 \%$ 들어간 $\mathrm{PBF}-2$ 조성에서 $864 \mathrm{kgf} / \mathrm{cm}^{2}$ 로 가장 높은 강도값을 나타 내었으며, 다시 함량 증가와 함께 감소하였다. 이는 기본 소지와 정수슬러지 하소분이 미세구조 내에서 결정상과 유리상이 가장 치밀하게 충진하였기 때문이다. $1260^{\circ} \mathrm{C}$ 에 서도 $1280^{\circ} \mathrm{C}$ 의 결과와 비슷한 경향을 보이는데, 같은 $\mathrm{PBF}-$ 2 조성에서 $836 \mathrm{kgf} / \mathrm{cm}^{2}$ 로 최고값을 나타낸 뒤 급격히 감 소하는 경향을 보였다. $1300^{\circ} \mathrm{C}$ 소성 시험편의 경우에는 전반적으로 함량 증가에 따라 강도값은 감소하는 경향을 보이는데, 높은 강도값을 보였던 PBF-2 조성에서도 소성 온도의 상승에 따른 유리상의 생성이 많아져 강도는 감 소하였다고 생각된다. 이와 같이 본 실험 조성 내에서는 강 도값은 정수슬러지 하소분의 함량 증가와 함께 감소하는 경향을 보이지만, 어느 쪽도 기존의 시판되어지고 있는 기 존의 조합토보다 월등히 우수한 강도값을 나타내고 있다.

소결온도에 따른 각 조성의 파단면에 의한 미세구조를 관찰한 결과, 정수슬러지 하소분의 함량 증가에 따라 기 공의 양과 크기가 증가하는 것이 관찰되어 이에 물성의

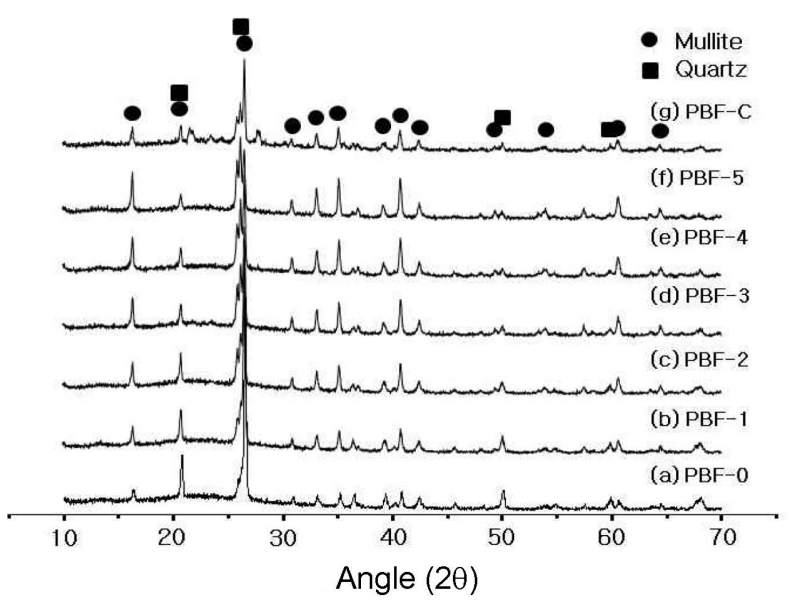

(a)

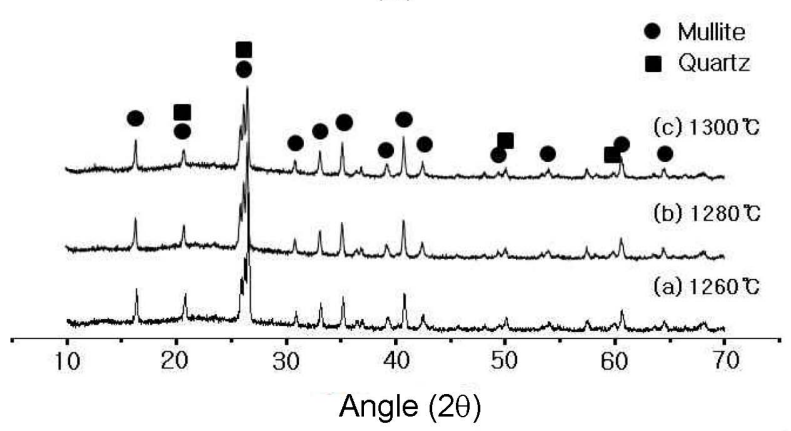

(b)

Fig. 7. X-ray diffraction patterns of (a) the specimens sintered at $1280^{\circ} \mathrm{C}$ with the different amount of water-pirifiedsludge and (b) PBF-3 at the different sintering temperatures.
변화에 영향을 미친 것으로 생각된다. Fig. 6 의 $1280^{\circ} \mathrm{C}$ 의 $\mathrm{PBF}-0$ 에서 PBF-3은 소결에 의한 치밀화가 진행되어져 상 대적으로 작고 적은 기공이 일부 존재하고 있는 형태이 나, 정수슬러지 하소분이 $40 \%$ 첨가된 PBF-4 조성부터는 기공의 양과 크기가 증가함에 의해 치밀하지 못한 미세 구조가 관찰되고 있다. 또한 각 소성온도별 미세구조 관 찰결과에서 정수슬러지 하소분이 $30 \%$ 인 PBF-3 조성의 경 우에서 보면 $1280^{\circ} \mathrm{C}$ 보다 $1300^{\circ} \mathrm{C}$ 의 소성온도에서 강도의 저하가 나타나며, 이는 소성온도의 상승에 따라 기공은 줄어드는 대신 유리상이 증가하여 특성의 저하에 영향을 미쳤다고 판단된다.

또한 이러한 강도의 변화에 대해 또 하나의 요인으로 생각되어지는 각 조성 시편의 소성에 의한 결정상의 변 화를 $\mathrm{X}$ 선회절분석으로 확인하고, 그 중 $1280^{\circ} \mathrm{C}$ 로 시험편 과 각 온도로 소성한 PBF-3 조성의 결과를 Fig. 7에 나타 내었고, 이 때의 각 시험편 내의 mullite의 양의 변화를 측정하여 그 결과를 Fig. 8에 나타내었다.

Fig. 7에서 보인 바와 같이 $1280^{\circ} \mathrm{C}$ 에서 소성한 모든 조 성에서는 기본적으로 mullite와 quartz상이 공존하는 것 으로 관찰되었으나, 정수슬러지 하소분의 함량 증가에 따 라 mullite양은 조금씩 증가하고 있는 것이 관찰되었다. 이러한 mullite양의 증가는 Fig. 8 의 $1280^{\circ} \mathrm{C}$ 소성 시험편 의 결정상 함량 분석 ${ }^{15)}$ 결과에서와 같이 기본소지에서 약 $25 \%$ 였던 mullite는 정수슬러지 하소분의 함량 증가와 함께 크게 증가하였다. 이 때 입성장한 mullite도 조금씩 증가하는 것이 관찰되었다. 이에 Fig. 5의 굽힘강도값 등 의 물성의 변화는, PBF-2, 3 조성에서 가장 치밀한 미세 구조를 보인 반면, 그 이상의 조성에서는 미세구조에서 의 mullite 및 기공의 증가와 미반응 정수슬러지 하소분 의 함량 증가 등에 의해 물성의 저하에 영향을 미쳤다 고 보여진다.

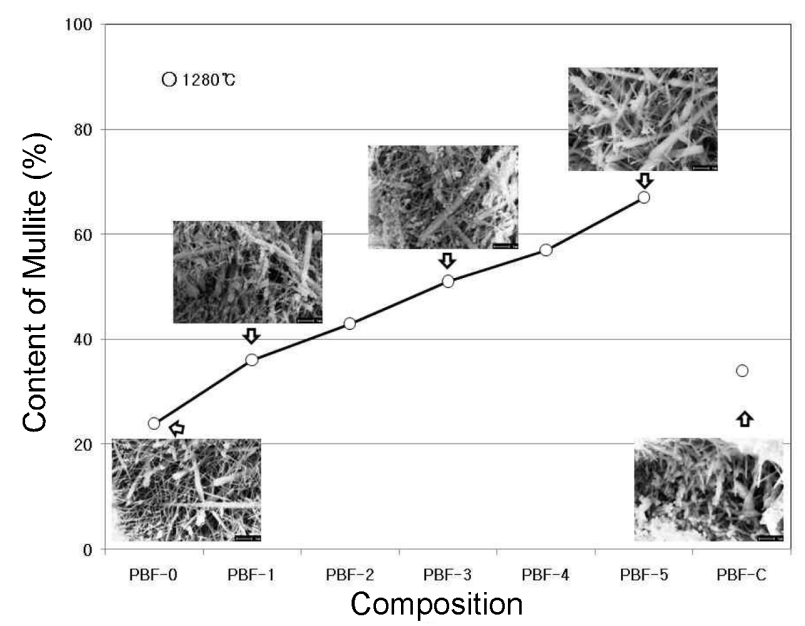

Fig. 8. Content of mullite for the different specimens sintered at $1280^{\circ} \mathrm{C}$ 


\section{4. 결 론}

물의 고도정수시설에서 발생하여 전량 직매립에 의해 폐기처분되고 있는 정수슬러지를 간단 처리하여 도자기 소지용 조합토의 원료로서 재활용하는 연구를 수행하고 다음과 같은 결론을 얻었다.

1. 정수슬러지를 열처리한 결과, $1150^{\circ} \mathrm{C}$ 이상에서 mullite 를 주결정상으로 하는 하소분이 되어 세라믹 원료로의 재 활용이 가능하나, 조합토 원료로서 활용하기 위해 열처리 온도는 일반적인 도자기 소성온도보다 높은 $1300^{\circ} \mathrm{C}$ 로 정 하였다.

2. 정수슬러지 하소분의 함량 증가에 따라 가소성은 감 소하여 PBF-3까지는 물레성형이 가능하나, 그 이상의 조 성에 있어서는 성형이 어려웠다. 이는 기본 소지에 가소 성점토 등의 첨가하는 실험으로 보완할 수 있을 것으로 보여진다.

3. 본 실험의 범위 내에서는 정수슬러지 하소분을 $20 \%$ 혼합한 $1280^{\circ} \mathrm{C}$ 의 $\mathrm{PBF}-2$ 조성에서 물레성형이 가능하고, 흡수율 $0.4 \%$, 기공율 $1.0 \%$ 이내이며, $864 \mathrm{kgf} / \mathrm{cm}^{2}$ 에 가까 운 높은 강도값을 나타내어, 이에 기존 조합토를 대체할 수 있는 소지로서 활용이 가능할 것으로 판단되었다.

\section{REFERENCES}

1. H. U. Hwang, J. H. Kim, and Y. J. Kim, "Recycling of Waterworks Sludge in Red Clay Bricks Manufacturing," $J$. Kor. Soc. Environ. Eng., 31 [3] 217-22 (2009).

2. K. S. You, G. C. Han, D. Y. Han, K. H. Cho, J. W. Ahn, and H. Kim, "Synthesis of Zeolite Using Sludge from Water Purification Plant to Use as a Environmental Remediation Material," Proc. Kor. Inst. Res. Recycling Conf., pp. 124-28 2006.

3. B. D. Lee, "Red-tide Removal by Solidated Water Treatment Sludge," J. Kor. Soc. Waste Manag., 23 [2] 91-96 (2006).
4. A. G. N. Othman, "Recycling of Spent Magnesite and ZAS Bricks for the Production of New Basic Refractories," Ceram. Int., 31 [8] 1053-59 (2005).

5. S. J. Im, H. Kim, and J. B. Lee, "Effects of Loess and Admixtures on Solidification of Waterworks Sludge," $J$. Kor. Soc. Water and Wastewater, 17 [6] 802-09 (2003).

6. S. H. Kim, "Treatment of Sludge from Water Treatment Plant," J. Kor. Soc. Civil Eng., 17 [2] $495-98$ (1997).

7. B. G. Lim and Y. T. Kim, "Characteristics of Soil-water Characteristic Curve and Unsaturated Permeability of Sludge Mixture," J. Kor. Geotechnical Soc., 29 [2] 57-64 (2013).

8. J. M. La, D. J. Choi, M. G. Kim, and J. M. Kim, "HydrationSetting Property of Slaked Lime and Artificial Zeolite Synthesized with Top Water Sludge," J. Kor. Recycl. Constr. Resour. Inst., 5 [4] 122-28 (2010).

9. H. J. Lee, "Assessment \& Sintering Brick Made from Recycling Material of Sewage Sludge Ash," J. Soc. Environ. Technol. Kor, 14 [4] 293-301 (2013).

10. Y. H. Oh, Y. R. Song, J. H. Lee, and D. H. Lee, "The Synthesis of Zeolite from Water Treatment Sludge and Absorption Characteristics of Ammonium Ion and Heavy Metals," J. Kor. Solid Waste Eng. Soc., 17 [2] 194-200 (2000).

11. Y. J. Kwon and B. H. Lee, "Recycling of the Wasted Bottom Ash for Roadbase Application," J. Kor. Soc. Waste Manag., 30 [1] 34-39 (2013).

12. B. D. Lee, "Red-tide Removal by Solidated Water Treatment Sludge," J. Kor. Soc. Waste Manag., 23 [2] 91-96 (2006).

13. H. B. Jun, Y. H. Kim, and D. S. Shur, "Drying and Thermal Characteristics of the Water Sludge," J. Kor. Solid Waste Eng. Soc., 11 [3] 456-95 (1994).

14. Y. T. Moon, "Settling Characteristics of Water Treatment Plant Sludges by Pretreatment Methods," J. Kor. Soc. Water and Wastewater, 22 [6] 627-32 (2008).

15. H. H. Shin, C. S. Kim, S. N. Chang, W. Sung, D. H. Chang, S. W. Kang, and S. H. Choi, "Quantitative Analysis of Hightemperature Mullitization from a Multicomponent Oxide System," J. Kor. Ceram. Soc., 35 [1] 5-10 (1998). 